\title{
EMOSI DALAM NASKAH DRAMA SAMPEK DAN ENGTAY KARYA NORBERTUS RIANTIARNO
}

\author{
Misnawati, Ellok Rahmawati
}

Universitas Palangka Raya (UPR) Kalimantan Tengah, Indonesia

Email: misnawati@pbsi.upr.ac.id, ellokrahmawati@gmail.com

\begin{abstract}
Abstrak
Naskah drama Sampek dan Engtay karya Norbertus Riantiarno terdapat berbagai jenis emosi yang membangun alur cerita di dalamnya. Hal inilah yang menjadi alasan peneliti menganalisis emosi yang terdapat dalam naskah drama ini. Tujuan penelitian ini adalah mendeskripsikan wujud emosi dalam naskan drama Sampek dan Engtay karya Norbertus Riantiarno. Teknik pengumpulan data dalam penelitian ini menggunakan: teknik pencatatan dan studi kepustakaan. Sumber data utama yang dianalisis adalah teks drama Sampek dan Engtay karya Norbertus Riantiarno. Data yang telah dikumpul dianalisis dengan menggunakan teori psikologi sastra. Teori psikologi sastra dimanfaatkan secara metodologis untuk menganalisis rumusan masalah penelitian. Hasil penelitian setelah dilakukan analisis data ternyata dalam naskah drama Sampek dan Engtay karya Norbertus Riantiarno ditemukan lima klasifikasi emosi, yaitu rasa bersalah tiga data, rasa malu lima data, kesedihan enam belas data, kebencian satu data, dan cinta lima belas data.
\end{abstract}

Kata Kunci: emosi; representasi; implikasi

\section{Abstract}

The scripts of the drama Sampek and Engtay by Norbertus Riantiarno have various types of emotions that build a story line in them. This is the reason for researchers to analyze the emotions contained in this drama script. The purpose of this study is to describe the form of emotions in the drama of Sampek and Engtay by Norbertus Riantiarno. Data collection techniques in this study using: recording techniques and literature study. The main data source analyzed was the drama text of Sampek and Engtay by Norbertus Riantiarno. The data collected was analyzed using the theory of literary psychology. Literary psychology theory is used methodologically to analyze the research problem formulation. The results of the research after analyzing the data turned out in the drama script Sampek and Engtay by Norbertus Riantiarno found five emotional classifications, namely guilt three data, shame five data, sadness sixteen data, hatred of one data, and love fifteen data.

Keywords: emotion; representation; implications

\section{Pendahuluan}

Emosi adalah suatu perasaan atau gejolak jiwa yang muncul di dalam diri seseorang sebagai akibat dari adanya rangsangan, baik dari dalam diri sendiri maupun

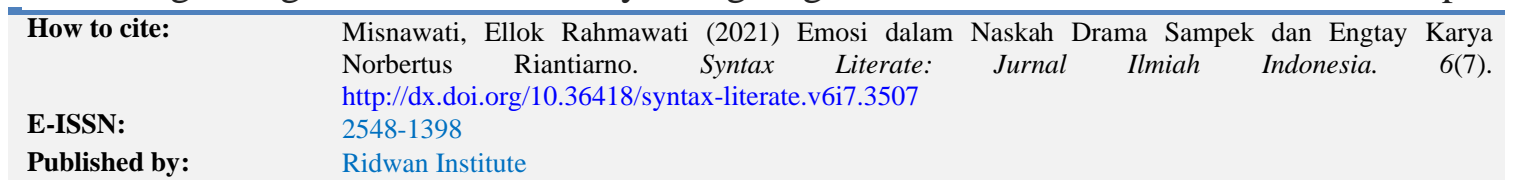


dari luar (Miswari, 2017). Emosi sangat berhubungan dengan kondisi psikologis dan suasana hati seseorang yang dinyatakan dalam bentuk perilaku tertentu. Perasaan emosi bisa berupa emosi positif (emosi yang baik), dan bisa berupa emosi negatif (emosi yang buruk). Banyak yang mengartikan kata "Emosi" sebagai bentuk amarah, namun sebenarnya kata emosi mewakili berbagai bentuk perasaan manusia seperti sedih, bahagia, dan marah.

Menurut (Krech, Crutchfield, \& Livson, 1974) kegembiraan, kemarahan, ketakutan, dan kesedihan kerap kali dianggap sebagai emosi yang mendasar (primary emotions). Situasi ini yang membangkitkan perasaan-perasaan tersebut sangat terkait dengan tindakan yang ditimbulkannya dan mengakibatkan meningkat ketegangan. Selain itu, juga rasa benci, iri hari, jengkel, cemburu juga termasuk ke dalam emosi kemarahan. Perasaan-perasaan ini yang nantinya apabila diungkapkan lewat tindakan maka akan menimbulkan sebuah ketegangan. Setelah perasaan ini terlampiaskan maka ada beberapa akibat yang akan ditimbulkan, diantara adalah perasaan bersalah, menyesal, dan sedih. Selain emosi-emosi kemarahan ini, ada juga beberapa emosi yang selalu melekat dalam diri manusia yaitu rasa cinta. Rasa cinta ini termasuk dalam klasifikasi emosi kegembiraan. Karena pada dasarnya rasa cinta yang dimiliki oleh seseorang akan selalu menimbulkan kegembiraan dalam diri orang tersebut. Maka dari itu manusia tidak akan pernah bisa lepas dari perasaan cinta, karena dengan perasaan cinta ini manusia bisa hidup dengan damai.

Masih terkait emosi, dalam naskah drama emosi tidak lepas dari psikologi sastra. Supaya mengetahui lebih lanjut apa itu "emosi", terlebih dahulu kita akan membahas tentang psikologi kepribadian. Psikologi kepribadian adalah psikologi yang mempelajari kepribadian manusia dengan objek penelitian faktor-faktor yang memengaruhi tingkah laku manusia (Papalia, Feldman Duskin, \& Martorell, 2015). Dalam psikologi kepribadian dipelajari kaitan antara ingatan atau pengamatan dengan perkembangan, kaitan antara pengamatan dengan penyesuaian diri pada individu, dan seterusnya. Sasaran pertama psikologi kepribadian ialah memperoleh informasi mengenai tingkah laku manusia. Karya-karya sastra, sejarah, dan agama bisa memberikan informasi berharga mengenai tingkah laku manusia (Koswara, 1991). Sasaran kedua, psikologi kepribadian mendorong individu agar dapat hidup secara utuh dan memuaskan, dan yang ketiga, sasaran ialah agar individu mampu mengembangkan segenap potensi yang dimilikinya secara optimal melalui perubahan lingkungan psikologis.

Bagi para psikoanalisis, istilah kepribadian adalah pengutamaan alam bawah sadar (unsconscious) yang berada di luar sadar, yang membuat struktur berpikir diwarnai emosi (Fazalani, 2021). Mereka beranggapan, perilaku seseorang sekadar wajah permukaan karakteristiknya, sehingga untuk memahami secara mendalam kepribadian seseorang, harus diamati gelagat simbolis dan pikiran yang paling mendalam dari orang tersebut. Mereka juga memercayai bahwa pengalaman masa kecil individu bersama orang tua telah membentuk kepribadian kita.

Psikologi sastra sering disebut juga sebagai psikoanalisis. Psikoanalisis adalah disiplin ilmu yang dimulai sekitar tahun 1900-an oleh Sigmund Freud (Fajriyah, 
Mulawarman, \& Rokhmansyah, 2017). Teori psikoanalisis berhubungan dengan fungsi dan perkembangan mental manusia (Abraham, 2017). Ilmu ini merupakan bagian dari psikologi yang memberikan kontribusi besar dan dibuat dalam psikologi manusia selama ini.

Setiap karya sastra pasti melibatkan emosi pengarang dalam membangun cerita yang ada di dalam karya sastra tersebut. Tanpa adanya emosi dalam pembuatan alur ceritanya, maka akan terasa hambar bagi para penikmat sastra itu sendiri. Alasan inilah yang membuat peneliti memfokuskan penelitian ini pada emosi dalam naskah drama Sampek dan Engtay karya Norbertus Riantiarno dan implikasinya pada pembelajaran sastra di SMA (Nirmala, 2009).

Berdasarkan uraian yang telah dipaparkan dapat disimpulkan kalau emosi merupakan perasaan yang muncul karena ada suatu kejadian yang memacu seseorang untuk mengeluarkan sebuah reaksi bisa positif bisa negatif.

Tujuan penelitian ini adalah (1) mendeskripsikan wujud emosi dalam naskan drama Sampek dan Engtay karya Norbertus Riantiarno. (2) Mendeskripsikan implikasi analisis emosi dalam naskah drama Sampek dan Engtay karya Norbertus Riantiarno pada pembelajaran sastra di SMA.

\section{Metode Penelitian}

Penelitian ini menggunakan pendekatan kualitatif. Penelitian kualitatif merupakan cara untuk menafsirkan dan menyajikan data dalam bentuk deskriptif (Ratna, 2013). Data-data yang telah ada kemudian ditafsirkan dan dianalisis untuk mendapatkan struktur emosi.

Metode deskripsi analisis bisa didapatkan dari penggabungan dua metode yang saling mendukung (Ratna, 2013). Kedua metode tersebut bertujuan untuk menguraikan informasi mendetail mengenai aspek-aspek struktur karya sastra dan menghubungkannya menjadi satu kesatuan yang memunculkan kalsifikasi emosi. Sumber data yang digunakan ialah catatan pada kartu data yang dikumpulkan peneliti. Teknik analisis data yang digunakan model analisis isi. Model analisis isi menekankan pemaknaan isi komunikasi dan isi interaksi simbolik yang terjadi pada peristiwa komunikasi yang ada dalam naskah drama.

\section{Hasil dan Pembahasan}

\section{A. Hasil Penelitian}

1. Wujud Emosi Tokoh yang Terdapat Dalam Naskah Drama Sampek dan Engtay Karya Norbertus Riantiarno

a. Rasa Bersalah

Rasa bersalah merupakan emosi yang dimiliki oleh seseorang ketika ia melakukan sebuah kesalahan baik yang disengaja maupun yang tidak sengaja (Hidayati, Wardiah, \& Ardiansyah, 2021). Setelah ia melakukan kesalahan tersebut timbullah di dalam dirinya sebuah penyesalan dan sering 
kita sebut sebagai rasa bersalah. Seseorang yang merasa bersalah pastinya ia akan meminta maaf kepada orang yang telah ia sakiti.

b. Rasa Bersalah yang Dipendam

Rasa bersalah yang dipendam merupakan perasaan yang timbul ketika ia melakukan sebuah kesalahan namun ia tidak mengakui bahwa ia yang telah melakukan kesalahan tersebut. Biasanya orang seperti ini adalah orang yang memiliki hati keras, ia tidak pernah meminta maaf kepada orang yang telah dilukainya dan ia hanya memendam perasaan bersalah itu tanpa mau disalahkan atas perbuatannya itu.

c. Menghukum Diri Sendiri

Menghukum diri sendiri adalah emosi yang timbul di dalam diri manusia ketika ia melakukan sebuah kesalahan dan ia tidak memperbaiki kesalahannya maka ia akan memutuskan untuk menghukum diri sendiri, seperti mengurung diri di dalam kamar tanpa mau minum atau makan, tidak mau bertemu dengan orang lain, maunya hanya sendiri tanpa mau diganggu oleh orang lain (Handayani, 2018). Bahkan ada yang sampai mengakhiri hidupnya akibat sebuah penyesalan tersebut.

d. Rasa Malu

Rasa malu merupakan emosi yang timbul ketika seseorang penyandang rasa malu secara alamiah ingin menyembunyikan diri dari orang lain karena perasaan tidak nyaman jika perbuatannya diketahui oleh orang lain. Misalnya dalam naskah drama Sampek dan Engtay, rasa malu ini dialami oleh Macun yang ketika ia ditanya oleh ayahnya, apakah ia mencintai Engtay, Macun tersenyum malu-malu.

e. Kesedihan

Rasa sedih ini timbul ketika seseorang merasa kehilangan sesuatu yang dicintainya atau sesuatu yang sangat berharga. Rasa sedih yang timbul dalam naskah drama Sampek dan Engtay ditunjukkan ketika Sampek mendengar bahwa Engtay telah dilamar Macun, dan masih banyak lagi kesedihan yang muncul di dalam naskah drama ini. Peneliti akan membahas pada bagian selanjutnya.

f. Kebencian

Kebencian adalah sebuah emosi kemarahan yang membuncah dalam jiwa seseorang. Kebencian terjadi ketika sesuatu yang berharga miliknya direbut oleh orang lain kemudian ia tidak terima dengan hal itu, dan pada akhirnya ia ingin menghancurkan orang yang telah merebut miliknya. Kebencian dalam naskah ini tampak ketika Macun melihat Engtay yang masuk ke dalam kuburan Sampek dan kuburan itu tidak bisa dibuka kembali. Dan akhirnya ia kehilangan Engtay, orang yang ia cintai, untuk selamanya.

g. Rasa Cinta

Rasa cinta merupakan emosi dasar yang dimiliki oleh manusia. Sekejam-kejamnya manusia pasti masih memiliki rasa cinta. Rasa cinta bisa 
timbul dengan cara lembut dan dengan cara menggebu-gebu. Rasa cinta yang muncul dengan cara lembut itu seperti ketika ayah Engtay tidak setuju dengan permintaan Engtay untuk sekolah, walaupun ayah Engtay tidak setuju namun setelah dibujuk akhirnya ayah Engtay mengabulkan keinginannya meski dengan hati yang berat, walaupun begitu ayah Engtay tetap mengusahakan yang terbaik untuk anak semata wayangnya itu. Rasa cinta yang timbul dengan cara menggebu-gebu dalam naskah ini terjadi ketika Engtay membongkar jati drinya kepada Sampek bahwa ia adalah seorang perempuan. Setelah mengetahui hal itu Sampek dan Engtay pun saling jatuh cinta hingga membuat mereka lupa diri dan ingin melakukan hal yang tidak senonoh.

Paparan data yang telah dipaparkan memberikan gambaran mengenai wujud emosi tokoh yang terdapat dalam naskah drama Sampek dan Engtay karya Norbertus Riantiarno. Wujud emosi tokoh itulah yang membangun cerita dalam naskah drama Sampek dan Engtay menjadi sebuah cerita yang apik dan tak pernah lekang oleh waktu. Wujud emosi tokoh dalam naskah drama Sampek dan Engtay karya Norbertus Riantiarno ini yang nantinya akan diimplikasikan pada pembelajaran sastra di SMA.

\section{B. Pembahasan}

\section{Wujud Emosi Tokoh dalam Naskah Drama Sampek dan Engtay karya Norbertus Riantiarno}

Naskah drama Sampek dan Engtay karya Norbertus Riantiarno ditulis pada tahun 1989, pertama kali dipentaskan oleh Teater Koma. Tokoh dalam drama ini berjumlah 19 orang yang berdialog, yaitu Dalang (narrator), Sampek (pemuda 20 tahun), Engtay (pemudi 17 tahun), Macun (tunangan Engtay), Juragan Ciok (ayah Engtay), Nyonya Ciok (ibu Engtay), Nio (ayah Sampek), Nyonya Nio (ibu Sampek), Sukiu (bujang Sampek), Jinsim (pengasuh Engtay), Suhiang (pelayang Engtay 17 tahun), Antong (Suami Jinsim), Kapten Liong (ayah Macun), Guru (berusia +50 tahun), Romeo, Juliet, Roromendut, Pronocitro, Adipati Wiraguna. Sedangkan yang tidak berbicara ada 6 golongan, yaitu murid-murid Sekolah Yayasan Putera Bangsa, rombongan arak-arakan, para pengangkat tandu, para pengawal tandu, pengiring tandu pengantin, dan penggali kubur.

Data yang ditemukan mengenai wujud emosi tokoh dalam naskah drama Sampek dan Engtay karya Norbertus Riantiarno adalah sebagai berikut.

a. Tokoh Sampek, ditemukan 1 data rasa malu, kesedihan 6 data, cinta 3 data.

b. Tokoh Engtay, ditemukan rasa bersalah 2 data, rasa malu 1, kesedihan 7 data, cinta 6 data.

c. Tokoh Macun, ditemukan rasa malu 1 data dan kebencian 1 data.

d. Tokoh Juragan Ciok, ditemukan rasa bersalah 1 data dan rasa cinta 1 data.

e. Tokoh Nyonya Ciok, ditemukan kesedihan 1 data dan cinta 2 data.

f. Tokoh Nyonya Nio, ditemukan kesdihan 1 data dan cinta 1 data.

g. Tokoh Nio, ditemukan kebencian 1 data. 
h. Tokoh Sukiu, ditemukan kesedihan 1 data.

i. Tokoh Jinsim, ditemukan rasa malu 2 data.

j. Tokoh Romeo, ditemukan rasa cinta 1 data.

k. Tokoh Juliet, ditemukan rasa cinta 1 data.

Pada paparan data di atas tokoh yang memiliki emosi yang sesuai dengan teori kalsifikasi emosi David Krech yang sudah dimodifikasi oleh Albertine Minderop hanya 11 tokoh, selebihnya belum data-datanya belum memenuhi kriteria klasifikasi emosi tersebut. Klasifikasi yang dimiliki para tokoh dalam naskah drama Sampek dan Engtay yaitu, emosi rasa bersalah, rasa malu, kesedihan, kebencian dan cinta. Sedangkan rasa bersalah yang dipendam dan menghukum diri sendiri tidak ditemukan dalam naskah drama ini. Wujud emosi tokoh dalam penelitian ini keseluruhan data berjumlah: 3 data rasa bersalah, 5 data rasa malu, 16 data kesedihan, 1 data kebencian, dan 15 data cinta.

Dalam penelitian ini setiap data diberikan kode, yaitu RB (Rasa Bersalah), RM (Rasa Malu), KS (Kesedihan), KB (Kebencian), RC (Rasa Cinta). Berikut pembahasan lebih lengkapnya.

\section{a) Tokoh Sampek}

\section{$>$ Rasa Malu}

Data 1 (RM)

Sampek: "Aku juga malu...."

(Riantiarno, 2019)

Pada data ini rasa malu dialami oleh tokoh Sampek yang pada saat itu ia ingin melakukan hubungan terlarang demi mengungkapkan rasa cintanya yang meledak-ledak antara Sampek dan Engtay. Berhubung ini adalah pertama kali bagi Sampek, dan Sampek juga merupakan pemuda yang sangat-sangat polos, maka timbullah dialog “Aku juga malu....”. Dialog ini menjelaskan bahwa Sampek masih malu-malu untuk melakukan hal itu, karena itu yang pertama baginya.

\section{Kesedihan}

Data $1(\mathrm{KS})$

Sampek: (MENANGIS MENYANYI)

Apa betul kita tidak mempunyai kesanggupan

Membalik langit, mengaduk lautan?

Apa para dewa juga ikut senang

Melihat sepasang kekasih berpisah?

(Riantiarno, 2019)

Data di atas menjelaskan bahwa Sampek sedang bersedih karena ia tidak bisa bersatu dengan Engtay. Dalam kalimatnya "Apa betul kita tidak mempunyai kesanggupan, membalik langit, medangaduk lautan?" kalimat ini menyatakan sebuah pertanyaan Sampek yang artinya apakah mereka (Sampek dan Engtay) tidak memiliki kesanggupan untuk mengubah hal yang sangat tidak mungkin terjadi, menjadi hal yang 
mungkin. Sampek sangat mengharapkan kalau Engtay tidak dijodohkan oleh orang tuanya dengan Macun, melainkan dijodohkan dengan dirinya. Data 2 (KS)

Sampek: (SEDIH) "kamu betul. Adikku, Engtay, mengapa kamu harus dipanggil

pulang?

(Riantiarno, 2019)

Pada data di atas kesedihan dirasakan oleh tokoh Sampek yang saat itu baru saja mengetahui bahwa Engtay adalah perempuan, baru saja ingin memadu kasih dan akhirnya mereka saling jatuh cinta. Namun, ketika mereka hendak memadu kasih di kamar, tiba-tiba Sukiu memberitahukan bahwa pengasuh Engtay datang untuk menjemput Engtay dan menyuruhnya pulang atas dasar perintah dari orang tua Engtay. Mengetahui hal itu Sampek sangat sedih karena harus berpisah dengan Engtay sesosok yang baru saja ia tetapkan sebagai belahan jiwanya. namun takdir berkata lain, takdir mengharuskan kisah cinta mereka menemui jalan yang amat terjal.

Data 3 (KS)

Sampek: "Engtay, Engtay, tega sekali kamu memutuskan hubungan kita. $\mathrm{Oh}, \mathrm{aku}$

tidak sanggup menyaksikan kau bersanding dengan lelaki lain, diiringi musik, berpakaian merah penuh ronce emas. Aku tidak sanggup lagi. Lebih baik mati, mati..."

(Riantiarno, 2019)

Pada data di atas menunjukkan Sampek sedang sakit dan meratapi perpisahannya dengan Engtay. Setelah ia mengetahui bahwa Engtay sudah ditunangkan oleh macun Sampek merasa frustasi dan ia rasanya tidak ingin hidup lagi. Lebih baik ia mati dari pada melihat Engtay menikah dengan lelaki lain dengan diiringi music, dan berpakaian merah penuh ronce emas. Ia tidak ingin melihat hal itu terjadi. Sampek tidak sanggup melihat Engtay bahagia dengan lelaki lain, selain dirinya.

Data 4 (KS)

Sampek: "Engtay, Engtay, aku memang bodoh. Tapi apa harus seberat ini

penderitaan yang mesti kutanggung akibat kebodohanku itu? Aku tidak sanggup, tidak sanggup...."

(Riantiarno, 2019)

Data ini menunjukkan bahwa Sampek terus menerus menyebutkan nama Engtay dikala sakitnya dan menyesali kebodohannya. Sampek tidak datang dihati yang telah dijanjikan oleh Engtay. Sampek Akibat kebodohannya itulah Sampek tidak bisa melamar Engtay dan malah Engtay lebih dulu dilamar oleh laki-laki lain. Sampek terus merutuki 
dirinya yang bodoh itu, ia bahkan tidak sanggup menerima penderitaan tersebut.

Data $5(\mathrm{KS})$

Sampek: "Aku tidak sanggup, mati saja, mati... aduh... sakiiiitt...."

(Riantiarno, 2019)

Data di atas menunjukkan bahwa sudah pada puncaknya Sampek tidak sanggup lagi untuk hidup dan menerima penderitaan itu, ia merasa bahwa ia lebih baik mati saja.

Data 6 (KS)

Sampek: "Dengar semua pesanku! Kuburanku akan seperti apa yang ditulis

Engtay dalam surat itu. Aku yakin, Engtay pasti akan datang ke kuburanku. (MENGAMBIL TUSUK KONDE DARI BALIK BANTALNYA) itu tusuk konde, tanda mata dari Engtay. Taruhlah di atas piring pedupan di depan kuburanku. Jika dia datang, dia pasti tahu apa yang harus dilakukannya. Ibu, ayah, aku mohon maaf karena tidak bisa menjaga sampai ayah, ibu tua. Maafkan anakmu yang tidak berbakti ini. Aku merasa, ajalku sudah dekat sekali. Ikhlaskan anakmu pergi, tapi ada satu permintaanku: jangan sampai benci sama Engtay, sebab dialah satu-satunya gadis yang paling aku cintai. Selamat tinggal semuanya... (SAMPEK MATI. TANGISPUN MELEDAK)

(Riantiarno, 2019)

Data ini menunjukkan bahwa ini adalah dialog Sampek diakhir hayatnya yang sangat menyedihkan itu, ia tidak dipersatuan dengan Engtay oleh Tuhan di dunia. Di akhir hayatnya Sampek meminta sebuah persarayatan yang ditulis oleh Engtay di suratnya. Meskipun begitu diakhir hayatnya ia tetap mencintai Engtay, hal ini dibuktikan ketika Sampek miminta orang tuanya untuk membuat kuburannya seperti yang diminta Engtay di suratnya.

\section{Cinta}

Data 1 (RC)

Sampek: "Aku mencintaimu."

(Riantiarno, 2019)

Pada data ini menunjukkan Sampek mengungkapkan bahwa ia mencintai Engtay.

Data 2 (RC)

Sampek: "Lelaki yang jatuh cinta biasa memakai kata-kata berbunga. Aku tidak.

Apa saja yang kukatakan, memang begitu kenyataannya."

(Riantiarno, 2019)

Data di atas menunjukkan bahwa ketika Sampek mencintai seseorang ia tidak pernah bermuluk-muluk atau mengungkapkan hal-hal yang indah 
namun bohong. Sampek menyatakan bahwa apa yang dia katakana itulah yang ia rasakan.

Data 3 (RC)

Sampek: "Ibu tidak pernah jumpa dengan dia sih. Pokoknya, untukku Engtay tak

bisa digantikan oleh siapapun."

(Riantiarno, 2019)

Data di atas menunjukkan bahwa Sampek menyatakan dengan tegas kepada ibunya bahwa tidak ada seorang wanitapun yang bisa menggantikan Engtay di hatinya.

\section{b) Tokoh Engtay}

Rasa Bersalah

Data $1(\mathrm{RB})$

Engtay: "Maafkan anakmu yang durhaka, Ibu. Ayah yang medorongku berbuat

seperti ini. Ayah pernah bilang akan mengizinkan aku sekolah ke Betawi kalau aku berhasil menipunya...."

(Riantiarno, 2019)

Data di atas menunjukkan bahwa Engtay merasa bersalah karena telah menipu ayahnya. Ia pura-pura menjadi seorang lelaki demi mendapatkan izin dari orang tuanya untuk sekolah. Pada saat itu perempuan dilarang untuk sekolah dan hanya boleh di dalam rumah saja, bahkan pergaulan dengan teman pun dibatasi.

Data 2 (RB)

Engtay: "Ayah, maafkan Engtay."

(Riantiarno, 2019)

Pada data ini Engtay benar-benar meminta maaf kepada ayahnya karena ia membuat ayahnya terkejut hingga pingsan.

\section{Rasa Malu}

Data $1(\mathrm{RM})$

Engtay: "Ah, aku malu."

(Riantiarno, 2019)

Pada data ini rasa malu dialami oleh tokoh Engtay yang pada saat itu ia dan Sampek ingin melakukan sesuatu yang melanggar aturan. Mereka hampir saja melakukan hal yang melanggar aturan demi mengungkapkan rasa cintanya yang terlalu mengebu-gebu.

Kesedihan

Data $1(\mathrm{KS})$

Engtay: (Menyanyi)

Menunggu ...

Rinduku, kasihku ...

Masa depan cintaku 
Panjang dan berliku-liku

Masa depan cintaku

Nampak semakin tak menentu

Menunggu ...

Rinduku, kasihku ...

Wajah masa depanku

Buram dan tak berwujud

Wajah masa depanku

Suram dan penuh kemelut ...

(Riantiarno, 2019)

Pada data ini menunjukkan kesedihan yang dialami oleh Engtay karena seorang yang ditunggunya tak kunjung tiba. Engtay sangat khawatir jika Sampek tidak datang tepat waktu sesuai dengan perjanjiannya, maka ia akan lebih dulu dilamar oleh Macun.

Data 2 (KS)

Engtay : (Menangis. Lari Ke Dalam)

(Riantiarno, 2019)

Pada data ini rasa sedih dialami oleh Engtay yang pada saat itu Macun dan ayah Macun datang ke rumah Engtay berniat untuk melamar Engtay. Namun pada saat itu hati Engtay benar-benar gundah gulana. Ia sangat terpaksa mengikuti kehendak orang tuanya untuk menerima perjodohan itu. Yang bisa dilakukan Engtay hanya diam dan menangis karena sudah tidak kuat lagi menahan emosinya dan ia memutuskan untuk lari ke dalam kamar.

Data $3(\mathrm{KS})$

Engtay: "Ah, Sampek. Kamu membuat hatiku hancur berkaping-keping." (Riantiarno, 2019)

Pada data ini rasa sedih dialami oleh tokoh Engtay karena mendengar penjelasan Sampek yang mengatakan bahwa ketika ditinggal oleh Engtay, Sampek merasa bahwa hidupnya taka da gunanya lagi tanpa Engtay di sisinya.

Data 4 (KS)

Engtay: (MENANGIS) "Tidak salah. Memang begitu kenyataanya."

(Riantiarno, 2019)

Data ini menjelaskan bahwa kesedihan yang dialami Engtay ketika Sampek mengatahui bahwa ternyata Engtay sudah ditunangkan oleh lakilaki lain yaitu Macun. Mendengar hal itu Sampek tidak percaya dan menanyakannya langsung kepada Engtay, dan Engtay meng-iya-kan berita itu.

Data 5 (KS)

Engtay: (Menangis) Ah, Sampek. Barangkali kita memang tidak berjodoh. 
Kalau tidak, mana mungkin kita harus menjalani lakon seperti ini. Tapi kalau boleh aku bilang, ini semua lantaran kebodohan kakak yang sangat kelewatan.

Ingatkah pesanku agar kau datang jangan lebih dari 2 dan 8, 3 dan 7, 4 dan 6 hari? Kau datang terlambat sekali."

(Riantiarno, 2019)

Pada data ini Engtay menangis ketika menjelaskan bahwa akibat kebodohan Sampek yang datang terlambat, tidak sesuai dengan hari yang dijanjikan oleh Engtay. Akibatnya Sampek tidak bisa meminang Engtay dan mereka tidak bisa bersatu. Karena pada saat itu Engtay sudah ditunangkan oleh laki-laki lain.

Data $6(\mathrm{KS})$

Engtay: (Menangis. Menyanyi)

Segalanya sudah terlanjur

Ibarat nasi sudah jadi bubur

Apalagi yang perlu disesali, apalagi?

Jodoh kita nyatanya bukan untuk zaman ini

(Riantiarno, 2019)

Dalam nyanyian ini Engtay mengatakan dengan kesedihan yang amat dalam bahwa ia dan Sampek memang tidak ditaksirkan oleh Tuhan berjodoh saat itu. Sampek dan Engtay sudah tidak bisa melakukan apaapa untuk mempertahankan hubungan mereka. semuanya sudah terlanjur, nasi sudah menjadi bubur dan tidak mungkin untuk diubah lagi.

Data 7 (KS)

Engtay : (Menangis Lari Ke Dalam Kamar)

(Riantiarno, 2019)

Data ini menunjukkan bahwa hati Engtay merasakan kesakitan yang amat dalam. Ia tidak bisa menerima lamaran Sampek lantaran ia sudah ditunangkan oleh Macun. Karena ia tidak sanggup melihat Sampek yang tengah patah hati pula.

\section{Cinta}

Data 1 (RC)

Engtay: (MENGALIHKAN PERSOALAN) "Lihat belibis-belibis itu. Asyik

berenang dan tidak peduli sekeliling. Lihat sepasang angsa itu, mereka dekat satu sama lain seakan tidak mau lepas. Mereka sedang berpacaran. Aih, kalau saja kita bisa seperti angsa itu. Dekat satu sama lain, saling mencintai. Kita masing-masing belum terikat, sendiri dan belum punya pasangan. Seharusnya kita juga bisa saling berpasangan."

(Riantiarno, 2019) 
Pada data ini menunjukkan bahwa Tokoh Engtay sedang berusaha untuk mengungkapkan perasaan cintanya kepada Sampek. Dengan sebuah pengibaratan-pengibaratan yang indah.

Data 2 (RC)

Engtay: "Baru kaulah lelaki yang kucintai."

(Riantiarno, 2019)

Data ini menunjukkan bahwa Engtay mengatakan bahwa Sampek adalah laki-laki pertama yang ia cintai.

Data 3 (RC)

Engtay: (TERLONGONG-LONGONG DI DEPAN KUBURAN SAMPEK) Aku datang padamu Sampek. Kemarin malam kau yang menemuiku dalam mimpiku. Begitu jelas, sampai aku tak tahu itu cuma mimpi atau memang kenyataan. Kau tidak berkata apa-apa selain menyebut namaku berulangkali. Kau tidak meminta apa-apa, tapi aku sangat paham apa yang kau kehendaki. Sekarang aku datang. Aku disini. Engtay: Sepanjang jalan aku semakin yakin, ternyata aku hanya mencintai

seorang lelaki, kaulah itu, Sampek. Dan bukan Macun. Kaulah yang seharusnya menjadi suamiku, dan bukan yang lainnya. (ENGTAY MENYOBEK KAIN YANG DIPAKAINYA DAN MENOREHKAN KATA-KATA DISITU DENGAN DARAH YANG DIAMBIL DARI UJUNG JARINYA) (LALU ENGTAY MEMBACA APA YANG SUDAH DITULISNYA ITU DENGAN SEDU SEDAN) "Hidup atau mati, kuingin selalu bersamamu. Tiada yang sanggup memisahkan cinta kita. Juga tidak kematian .. (MENUANG TIGA CAWAN ARAK, MENUMPAHKANNYA KE TANAH DI DEPAN KUBURAN SAMPEK) Terimalah arak persembahan. (MENANGIS) Sampek, Sampek, Sampek ...

(Riantiarno, 2019)

Data 4 (RC)

Engtay: Kau taruh tusuk kondeku disini. Aku tahu, apa yang kau harapkan

dariku. Sampek, kuambil tusuk konde ini. Akan kuketuk-ketuk di kuburannya Kalau kita memang berjodoh, kuburan ini pasti akan terbuka. Lalu aku akan masuk dan menjadi satu dengan jasadmu untuk selama-lamanya. Tapi kalau kita memang tidak berjodoh, tentu aku akan terus dibawa Macun ke Rangkasbitung dan jadi isterinya seumur hidup. Sampek, kau mati lantaran aku. Buktikan, bahwa kematianmu tidak siasia. Aku ketukkan tusuk konde ini tiga kali. Terbukalah ... Terbukalah kuburmu ini ... (MENGETUK-NGETUK TUSUK KONDE KEKUBUR SAMPEK, SEBANYAK TIGA KALI)

(Riantiarno, 2019) 
Data $5(\mathrm{RC})$

(TIBA-TIBA, SETELAH KETUKAN YANG KETIGA, TERDENGAR GELEGAR GUNTUR, PADAHAL LANGIT TIDAK SEDANG MENDUNG LALU SEBUAH CAHAYA, BAGAI METEOR, JATUH DARI LANGIT. CAHAYA ITU LANGSUNG MEMBENTUR KUBURAN SAMPEK, SEHINGGA KUBURAN JADI TERBELAH DAN MENGANGA) (ENGTAY TERKESIMA. SEMUA TERKESIMA)

(Riantiarno, 2019)

Data 6 (RC)

Engtay: (TERSENYUM) Kita memang berjodoh. Tunggu aku, Sampek! Aku

datang! (ENTAY MASUK KEDALAM KUBUR SAMPEK DENGAN GERAK YANG SANGAT INDAH SEKALI)

(Riantiarno, 2019)

Pada data 3, 4, 5, dan 6 ini Engtay menepati janjinya bahwa ia akan datang ketempat peristirahatan Sampek. Engtay menangis meraungraung ia mengatakan bahwa sepanjang perjalanan arak-arakan pernikahan Engtay dan Macun, Engtay semakin yakin bahwa hanya ada satu laki ia cintai, yaitu sampek. Setelah tibanya di kuburan Sampek, Engtay merobek kain suteranya dan menorehkan tulisan di perkuburan Sampek. Beberapa saat kemusian Engtay menyadari bahwa Sampek memang benar-benar melakukan apa yang diminta Engtay yaitu meletakkan tusuk konde Engtay yang pernah diberikan kepada Sampek. Tusuk konde itu oleh keluarga dan atas permintaan Sampek ditaruh diatas kuburannya. Setelah menyadari hal itu Engtay pun mengambil tusuk kondenya dan memukulkan tusuk konde itu sebanyak tiga kali, sambil mengatakan jika memang mereka berjodoh, maka kuburan itu terbuka dan jasad merekapun menyatu,. Namun jika kuburan itu tidak terbuka maka mereka memang tidak berjodoh, dan Engtay akan terus dibawa Macunke Rangkasbelitung. Seketika itu pula lengit menjadi mendung dan Guntur pun menggelerag dan tiba-tiba ada cahaya bagaikan meteor jatuh mengenai kuburan Sampek dan terbukalah kuburan itu. Mengetahui hal itu Engtay pun yakin bahwa mereka memang jodoh yang ditakdirkan oleh Tuhan. Engtay segera masuk ke dalam kuburan itu dan bersatu dengan jasad Sampek.

\section{c) Tokoh Macun}

\section{Rasa Malu}

Data $1(\mathrm{RM})$

Macun: "Ah, Ayah, bisa saja."

(Riantiarno, 2019) 
Rasa malu ini dialami oleh tokoh Macun ketika Kapten Liong mengatakan bahwa Macun telah mempersiapkan semua keperluan pernikahannya dengan Engtay. Bahkan Macun sudah membeli beberapa peralatan rumah tangga. Dan juga harga sewa tandu pengantin.

Kebencian

Data $1(\mathrm{~KB})$

Macun: (MELEDAK MARAH) "Jangan pedulikan! Bongkar!"

(Riantiarno, 2019)

Data ini menunjukkan bahwa Macun sangat murka melihat tunangannya di telah oleh kuburan Sampek. Sampek Murka dan menyuruh para penggali kubur untui membongkar kuburan itu dan menemukan orang yang sangat ia cintai itu.

\section{d) Tokoh Juragan Ciok}

\section{Rasa Bersalah}

Data 1 (RB)

Ciok: "Ini akibat kita turuti apa yang dia mau sejak kecil. Dia anggap semua

persoalan jalan keluarnya gampang-gampang saja. Kalau sekarang kita larang niatnya itu, aku takut nanti dia kaget. Lalu sakit, terus kalau dia sakit? Bagaimana? Dia anak kita satu-satunya...."

(Riantiarno, 2019)

Data ini menunjukkan bahwa Ciok sangat menyesal karena tela mendidik Engtay dengan menuruti semua keinginannya. Hingga pada saatnya tiba Engtay meminta sesuatu yang menurutnya akan membuat boomerang bagi keluarga mereka, dan jika keinginan Engtay tidak dituruti takutnya ia akan sakit. Ciok tidak ingin Engtay sampai sakit karena Engtay adalah anak satu-satunya dan sangat ia sayangi.

\section{Cinta}

Data 1 (RC)

Ciok: "Mau apa lagi? Kalau ibumu sudah setuju, masa aku tidak? Lebih baik

kamu siap-siap. Besok pagi kamu berangkat. Nanti ayah urus supaya kamu bisa langsung diantar kegedung sekolahan. Kebetulan ayah kenal baik guru kepala disana, ayah akan surati dia."

(Riantiarno, 2019)

Data ini menunjukkan bahwa Ciok sangat menyayangi anak semata wayangnya itu. Ciok akan mengabulkan semua permintaan Engtay meski hal itu melanggar aturan di zaman mereka. walaupun dengan terpaksa Ciok mengizinkan Engtay untuk pergi sekolah ke Betawi, Ciok tetap mengurus semua keperluan Engtay di Sana.

\section{e) Tokoh Nyonya Ciok}

$>$ Kesedihan 
Data $1(\mathrm{KS})$

Nyonya Ciok: (TERPENGARUH. IKUT MENANGIS) "Engtay, anakku. Apa

boleh buat. Ibu akan mengizinkan. Tapi kamu harus ekstra hati-hati. Waspada sama orang asing. Jangan terlalu cepat percaya sama orang yang baru kamu kenal. Betawi itu kota besar, jauh lebih gede dari Serang. Macam-macam orang berkumpul di kota itu, campur aduk kayak cendol. Kamu harus jeli memilih teman. Hemat pangkal pandai, rajin pangkal kaya. Harus patuh sama gurumu!"

(Riantiarno, 2019)

Data ini menunjukkan kesedihan yang dialami oleh Nyonya Ciok karena sebentar lagi ia akan ditinggalkan oleh anaknya pergi sekolah ke Betawi. Nyonya Ciok takut hal-hal buruk akan menimpa Engtay di tanah rantau yang merupakan sebuah kota besar, maka dari itu nyonya ciok memberikan banyak wejangan kepada Engtay agar terus berhati-hati dengan orang-orang di Betawi. Tidak bisa dipungkiri bahwa Nyonya Ciok sangat khawatir dengan keinginan Engtay kali ini.

\section{Cinta}

Data $1(\mathrm{KS})$

Nyonya Ciok: "Hatimu memang baik, dan aku percaya. Itu sebabnya aku dan

ayahmu memutuskan untuk tidak membuat kakimu kecil seperti yang sudah dilakukan oleh leluhur-leluhur kita. Lihat, kakiku sendiri masih kecil. Dan apa yang kami putuskan itu hanya menandakan kami sangat mencintaimu."

(Riantiarno, 2019)

Pada data ini Nyonya Ciok menyatakan bahwa semua hal yang dilakukan untuk Engtay adalah demi kebaikan dan kebahagiaan Engtay menurutnya. Ia tidak ingin anaknya bersaib sama sepertinya yang memiliki "kaki kecil" yang artinya ia tidak ingin Engtay seperti dirinya yang tidak bisa kemana-mana dan hidup sebagai seorang wanita yang hanya tahu kehidupan dikeluarganya saja, tanpa mengetahu betapa luasnya dunia ini untuk dilihat dan dikagumi. Maka dari itu ia menuruti semua yang diminta oleh Engtay dengan mudah.

Data 2 (KS)

Nyonya Ciok: (MEMELUK ENGTAY) "Anakku, buah hati, cahaya hidupku ...."

(Riantiarno, 2019)

Data ini menunjukkan bahwa rasa cinta seorang sangatlah besar terhadap anaknya. Seorang ibu pasti menganggap anaknya sebagai cahaya hidupnya dan sumber kebahagiannya.

\section{f) Tokoh Nyonya Nio}




\section{Kesedihan}

Data 1 (KS)

Nyonya Nio: (MENANGIS) “Aduh, Sampek, anakku, jangan begini nak. Kamu anakku satusatunya, bangkitlah semangatmu, nak. Jangan habis hanya lantaran cinta. Sampek, untuk apa mengingat-ingat gadis yang sudah bertunangan?"

(Riantiarno, 2019)

Pada data ini menunjukkan bahwa Nyonya Nio (ibu Sampek) sedih melihat anaknya yang sedang sakit-sakitan akibat patah hati. Nyonya Ciok terus memberikan semangat kepada anaknya untuk segera sembuh, demi kesembuhan anaknya ia menyuruh Sampek untuk melupakan Engtay yang sudah bertunangan itu.

\section{Cinta}

Data 1 (RC)

Nyonya Nio: “Apa gadis itu bisa meramal? Jangan dengarkan dia Sampek. Kau

pasti akan sembuh. Minumlah obat yang diberikan tabib Koh. Sesudah sembuh, ibu janji, akan mencarikan kamu gadis yang jauh lebih hebat dari Engtay. Sampek, sembuh nak, sembuh ya? Kasihani ibumu ...."

(Riantiarno, 2019)

Data ini menunjukkan rasa cinta Nyonya Nio kepada Sampek anaknya. Bahkan ia memanggilkan tabib untuk kesembuhan anaknya, ia tidak ingin melihat anaknya sakit-sakitan lantaran Sampek terus-menerus mengingat nama Engtay. Bahkan Nyonya Nio berjanji jika Sampek sembuh maka ia akan mencarikan gadis yang jauh lebih baik dari pada Engtay.

\section{g) Tokoh Nio}

\section{Kebencian}

Data $1(\mathrm{~KB})$

Nio: "Kurang ajar. Kurang ajar. Apa maksud dari surat itu? Sok pintar sekali.

Lebih pintar dari tabib yang paling pintar. Kurang ajar.”

(Riantiarno, 2019)

Data ini menunjukkan bahwa Nio (ayah Sampek) sangat marah kepada Engtay, lantaran surat yang dikirim Engtay untuk Sampek, yang menurutnya isi surat itu malah mendoakan Sampek agar cepat mati. Tidak ada satu pun orang tua yang terima jika anaknya didoakan cepat mati oleh orang lain, bahkan itu adalah orang yang sangat dicintai anaknya. Mungkin karena keburu emosi, maka ayah Sampek sangat marah mendengar hal itu dan malah salah mengartikan maksud dari surat Engtay tersebut. 


\section{h) Tokoh Sukiu}

Kesedihan

Data $1(\mathrm{KS})$

Sukiu: (MENANGIS. SAMBIL MENGHAPUS AIR MATA YANG MELELEH)

"Memang gadis ini teramat sangat kelewat kurang ajar. Ini namanya menyumpahi...."

(Riantiarno, 2019)

Data ini menjelsakan bahwa Sukiu juga ikut bersedih melihat surat dari Engtay untuk Sampek yang dibawanya. Tadinya ia berharap surat itu berisi doa yang atau kata-kata semangat untuk menyebuhkan Sampek, ternyata isi surat itu bertolah belakang dengan yang diharapkan. Ia sedih ketika melihat juragannya yang sangat ia sayangi disumpahi cepat meninggal oleh Engtay. Sukiu tidak terima dengan hal itu.

\section{i) Tokoh Jinsim}

$>$ Rasa Malu

Data $1(\mathrm{RM})$

Jinsim: (MALU-MALU) "Nyonya Besar ...."

(Riantiarno, 2019)

Data ini menunjukkan rasa malu yang dialami oleh tokoh Jinsim ia menyampaikan keinginnya kepada Nyonya Ciok untuk ikut Antong pergi ke Betawi menjemput Engtay.

Data 2 (RM)

Jinsim: (MALU) "Maaf Nya Besar, tapi diizinkan ikut ya?"

(Riantiarno, 2019)

Data ini menunjukkan bahwa Jinsim tetap bersikukuh untuk ikut Antong ke Betawi dengan sikap yang sedikit malu-malu, takut kalau-kalau ia tidak diizinkan juragannya tersebut.

\section{j) Tokoh Romeo}

$>$ Cinta

Data $1(\mathrm{RC})$

Romeo: (MUNCUL BERSAMA YULIET) "Ibarat bunga, mawar ataupun

kenanga, kalau ia harum, nama tak lagi penting adanya. Yuliet, dikau ibarat bunga. Berganti nama sejuta kalipun, asal dikau adalah Yuliet seperti yang kukenal sekarang ini, duhai, dikau tetap kucinta ..." (Riantiarno, 2019)

Data ini menunjukkan bahwa Romeo sangat mencintai Yuliet. Hal ini dapat dilihat dari pengibaratan yang diberikan oleh Romeo kepada Yuliet, bahwa Yuliet ibarat bunga, mesipun berganti nama sejuta kalipun, asal itu adalah Yuliet seperti yang ia kenal sekarang, maka ia akan tetap mencintai Yuliet. 
k) Tokoh Juliet

Cinta

Data $1(\mathrm{RC})$

Juliet: (MANJA) "Ah, ah ...."

(Riantiarno, 2019)

Dialog di atas menggambarkan bahwa Yuliet salah tingkah dengan pernyataan cinta Romeo. Ia pun semakin mencintai Romeo karena ungkapan cintanya tersebut. hingga Engtay tidak memiliki kata-kata lain selain "Ah, ah..." yang dapat diungkapkannya. Hatinya sangat bahagia mendengar hal itu.

\section{Kesimpulan}

Wujud Emosi Tokoh dalam Naskah Drama Sampek dan Engtay Karya Norbertus Riantiarno dalam penelitian ini menggunakan teori klasifikasi emosi David Krech yang sudah dimodifikasi oleh Albertine Minderop, awalnya emosi terbagi menjadi tujuh bagian, yaitu rasa bersalah, rasa bersalah yang dipendam, menghukum diri sendiri, rasa malu, kesedihan, kebencian dan cinta. Namun, setelah dilakukan analisis data ternyata dalam naskah drama Sampek dan Engtay karya Norbertus Riantiarno hanya ditemukan lima klasifikasi emosi, yaitu rasa bersalah tiga data, rasa malu lima data, kesedihan enam belas data, kebencian satu data, dan cinta lima belas data. 


\section{BIBLIOGRAFI}

Abraham, Ihsan. (2017). Struktur kepribadian tokoh dalam novel Surat Kecil untuk Tuhan karya Agnes Davonar. Kembara, 3(1), 55-63. Google Scholar

Fajriyah, Khoiriyatul, Mulawarman, Widyatmike Gede, \& Rokhmansyah, Alfian. (2017). Kepribadian tokoh utama wanita dalam novel alisya karya muhammad makhdlori: kajian psikologi sastra. CaLLs (Journal of Culture, Arts, Literature, and Linguistics), 3(1), 1-14. Google Scholar

Fazalani, Runi. (2021). Menganalisis Novel "Cantik Itu Luka" Karya Eka Kurniawan Melalui Unsur Intrinsik Dan Menggunakan Psikoanalisis. Reform: Jurnal Pendidikan, Sosial, Dan Budaya, 4(01), 11-23. Google Scholar

Handayani, Nunung. (2018). Klasifikasi Emosi Tokoh Jati Dalam Novel Jangan Miringkan Sajadahmu Karya Muhammad B. Anggoro Ditinjau Dari Psikoanalisis Sastra Serta Hubungannya Dengan Pembelajaran Sastra Di SMA. Universitas Mataram. Google Scholar

Hidayati, Eka Suci, Wardiah, Dessy, \& Ardiansyah, Arif. (2021). Klasifikasi Emosi Tokoh Dalam Novel Titian Takdir Karya W Sujani (Kajian Psikologi Sastra). Jurnal Pendidikan Tambusai, 5(1), 2005-2017. Google Scholar

Koswara. (1991). Teori-Teori kepribadian. Bandung: PT. Gresco.

Krech, David, Crutchfield, Richard S., \& Livson, Norman. (1974). Elements of psychology. Alfred a. knopf. Google Scholar

Miswari, Miswari. (2017). Mengelola Self Efficacy, Perasaan dan Emosi dalam Pembelajaran melalui Manajemen Diri. Cendekia: Jurnal Kependidikan Dan Kemasyarakatan, 15(1), 67-82. Google Scholar

Nirmala, Afsun Aulia. (2009). Naskah drama sampek engtay karya n. riantiarno dan romeo juliet karya William shakespeare (tinjauan intertekstualitas, kajian feminisme, dan nilai edukatif). UNS (Sebelas Maret University). Google Scholar

Papalia, Diane E., Feldman Duskin, Ruth, \& Martorell, Gabriela. (2015). Perkembangan Manusia. 1-486.

Ratna, I. Nyoman Kutha. (2013). Teori, metode \& teknik penelitan sastra: dari strukturalisme hingga postrukturalisme: perspektif wacana naratif. Pustaka Pelajar. Google Scholar

Riantiarno. (2019). Norbertus. Diakses 10 Juni 2019. Google Scholar

Copyright holder:

Misnawati, Ellok Rahmawati (2021) 
Emosi dalam Naskah Drama Sampek dan Engtay Karya Norbertus Riantiarno

\section{First publication right:}

Syntax Literate: Jurnal Ilmiah Indonesia

This article is licensed under:
(c) (i) (2) 